\title{
Does human pancreas contain salivary-type isoamylase? ${ }^{1}$
}

\author{
JUNNOSUKE SHIMAMURA ${ }^{2}$, LOUIS FRIDHANDLER, AND J. EDWARD BERK \\ From the Division of Gastroenterology, Department of Medicine, College of Medicine, \\ University of California, Irvine, California, U.S.A.
}

SUMMARY Amylase isoenzyme analysis was made of extracts of normal human pancreatic tissue by first conducting ion exchange chromatography of the purified material. This gave evidence of only pancreatic type (P-type) isoamylase for all practical purposes. However, when effluent fractions in which salivary type isoamylase would ordinarily be expected to be present were harvested, pooled, concentrated, and rechromatographed, the pancreatic extracts were found to contain some salivary type (S-type) isoamylase. The latter accounted for approximately 0.8 to $1.7 \%$ of the total recovered amylase activity. This finding of S-type isoamylase in normal human pancreas potentially has important bearing on the interpretation of isoamylase analysis.

Studies were recently conducted by us in a patient with cancer of the pancreas associated with hyperamylasaemia and hyperamylasuria (Shimamura et al., 1975. The chromatogram resulting from the chromatographic procedure employed by us to separate the principal isoamylases (Fridhandler et al., 1972) did not exhibit any clearly discernible peak consistent with pancreatic type (P-type) isoamylase in the serum of this patient. A small peak of P-type isoamylase was apparent, however, in the urine chromatogram. The appearance of $\mathbf{P}$ type isoamylase in the urine indicated that some P-type component must be present in the serum even though not clearly demonstrated. The discrepant findings in the serum and urine were intriguing. We were also surprised to find that the hyperamylasaemia was dominantly due to S-type isoamylase, despite the presence of primary cancer of the pancreas. Both these findings, taken in conjunction with the fact that our earlier ion exchange chromatographic studies of the isoamylase content of normal human pancreas had shown some overlap of the pancreatic amylase peak into the salivary amylase area (Fridhandler et al., 1972), prompted us to reinvestigate the isoamylase composition of normal human pancreatic extract. This report describes these studies. Contrary to our initial impression (Fridhandler et al., 1972), the newer studies suggest that

\footnotetext{
ISupported by a grant from the John A. Hartford Foundation, Inc. 'Dr. Shimamura was partially supported by a grant from the Bockus International Society of Gastroenterology.

Received for publication 6 August 1975.
}

the pancreas probably contains a small amount of S-type isoamylase. It may well be necessary in the light of this finding to reconsider and reassess certain concepts that have evolved concerning isoamylase analysis and its clinical interpretation.

\section{Methods}

Pancreatic tissue was obtained at necropsy from four patients within $4 \frac{1}{2}$ hours after death and immediately frozen. In two of the cases, the pancreas was normal in appearance both grossly and microscopically. The other two specimens were obtained from individuals who had been killed in accidents and microscopic examination of the pancreas was not performed.

After thawing, the pancreatic tissue was carefully dissected from neighbouring tissue, weighed, and cut into small pieces. The latter were rinsed in a medium that contained $50 \mathrm{~m} \mathrm{~mol}$ Tris [Tris (hydroxymethyl) aminomethane], $\mathrm{pH} 7 \cdot 2$; benzamidine hydrochloride, $0.156 \mathrm{~g}$; sodium azide, $0.2 \mathrm{~g}$; and $\mathrm{NaCl}, 8.5 \mathrm{~g}$, in each litre. The cut pieces of tissue were blotted after rinsing. They were then placed in the rinsing medium and homogenized in a Teflon tissue grinder (Arthur H. Thomas) for three minutes in an ice bath. The homogenate was next centrifuged at 10000 rpm for 30 minutes at $4^{\circ} \mathrm{C}$.

The isoamylase pattern of the supernatant was studied by a chromatographic method using DEAESephadex A-50 (Fridhandler et al., 1972) but modified in that the $0.2 \mathrm{mM} \mathrm{CaCl}_{2}$ was omitted from 
Buffer B. Those fractions eluted from the ion exchange column in which S-type isoamylase would be expected to be present were isolated from the rest of the fractions. This was done to remove most of the overwhelming amount of P-type isoamylase and thus facilitate discernment of any small amount of S-type. The isolated fractions were pooled, concentrated, and then rechromatographed through the DEAE-Sephadex A-50 column. The chromatogram constructed by plotting the amylase values in each of the effluent fractions obtained after this manoeuvre were quantitated by determining the relative weights of the tracings of each peak (Fridhandler et al., 1972).

More detailed study of the isoamylase components recovered after rechromatography was also done in two of the cases using both Sephadex G-75 and DEAE-Sephadex A-50 as previously described by us (Fridhandler et al., 1974). Here again, however, the procedure was modified by omitting the $\mathrm{CaCl}_{2}$ from the buffer used in the ion exchange chromatography.

\section{Results}

The initial passage of the pancreatic homogenate

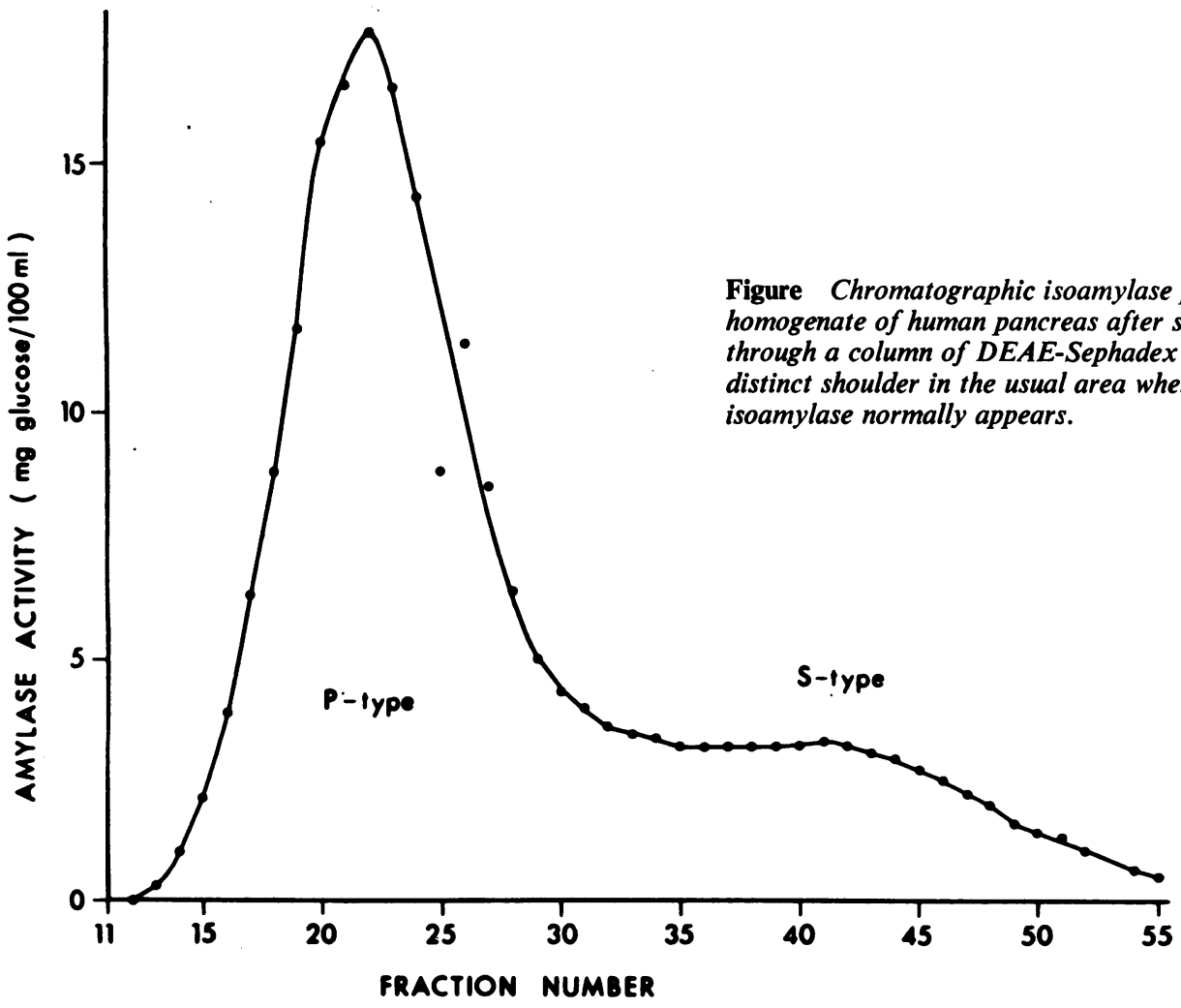

through DEAE-Sephadex A-50 resulted in a chromatogram that showed so little amylase activity in the fractions that ordinarily contain S-type isoamylase that the latter was interpreted as being absent for all practical purposes. Indeed, it was considered that the minute amount of amylase activity in these later fractions probably represented merely a trailing of the peak of P-type isoamylase (Fridhandler et al., 1972). The pattern after harvesting, concentrating, and rechromatographing these fractions was different. A distinct shoulder was now evident which was sufficiently distinct to warrant interpretation as a separate component of amylase consistent in its chromatographic position with that of S-type isoamylase (Figure). The calculated percentage of S-type isoamylase ranged from 0.8 to $1.7 \%$ of the total recovered amylase activity (Table).

Haemoglobin concentration in each supernatant of the pancreatic homogenates was measured to provide a measure of the amount of contamination by blood. This was used as a means of estimating the potential contribution of S-type isoamylase in the blood to the activity recorded for the pancreatic tissue homogenates. The haemoglobin in the pancreatic tissue ranged from 9 to $19 \mathrm{mg} / \mathrm{dl}$. These values were interpreted to indicate whole blood

igure Chromatographic isoamylase pattern of homogenate of human pancreas after second passage distinct shoulder in the usual area where S-type isoamylase normally appears.

\section{5}




\begin{tabular}{lclllll}
\hline Case & $\begin{array}{c}\text { Age } \\
(y r)\end{array}$ & Sex & $\begin{array}{l}\text { Condition of pancreatic } \\
\text { tissue }\end{array}$ & After death $(h r)$ & $\begin{array}{l}\text { Amylase activity of } \\
\text { pancreatic tissue }\end{array}$ & \% of S-type isoamylase \\
\hline 1 & 5 & F & $\begin{array}{l}\text { Grossly and micro- } \\
\text { scopically normal }\end{array}$ & 4 & 17160 & $1 \cdot 7$ \\
2 & 63 & M & $\begin{array}{l}\text { Grossly and micro- } \\
\text { scopically normal }\end{array}$ & 4 & 552500 & 0.8 \\
3 & 51 & M & $\begin{array}{l}\text { Grossly not remarkable } \\
\text { Grossly normal }\end{array}$ & $4 \frac{1}{3}$ & 422501 & 0.9 \\
4 & 21 & M & 426160 & $1 \cdot 2$ \\
\hline
\end{tabular}

*Expressed as mg glucose/100 g wet weight.

Table Pertinent data relating to specimens of human pancreatic gland studied

contamination too small to affect appreciably the percentage of S-type isoamylase found in the pancreatic homogenates. This conclusion seemed to be further supported by the low blood amylase level in comparison with the enormous level of amylase activity in pancreatic tissue (Table).

The more detailed analysis of the major isoamylase components revealed the presence in one case of isoamylase components A and B (P-type isoamylases) and a small peak of component D (an S-type isoamylase derivative) (Fridhandler et al., 1974). In the other case, a small amount of component C (an S-type isoamylase derivative) was found in addition to components $\mathrm{A}, \mathrm{B}$, and $\mathrm{D}$. The fractions containing component $\mathbf{D}$ in both cases were isolated, pooled, concentrated, and then rechromatographed through DEAE-Sephadex A-50. The results more clearly showed the existence of a separate peak of component $D$ and confirmed that it was not simply the slowly trailing terminal portion of the quantitatively greater component B, a P-type isoamylase derivative (Fridhandler et al., 1974).

\section{Discussion}

The source of P-type isoamylase in the serum and urine appears to be organ specific, since P-type isoamylase is absent in the serum and urine of patients who have undergone total pancreatectomy (Fridhandler et al., 1972). It was our impression also from single ion exchange chromatography of human pancreatic extract that the pancreas contained only P-type isoamylase. The data herein described make it appear that this concept is invalid. They suggest, rather, that the pancreas may have the capacity to synthesize S-type as well as P-type isoamylase.

Alternative theoretical possibilities to account for the recovery of S-type isoamylase in pancreatic extracts studied by the special means employed in these studies would include: (1) origination of the S-type isoamylase in blood contaminating the pancreatic homogenate, and (2) penetration of blood filtrates containing amylase but not haemoglobin into the intra- or extracellular spaces of the pancreas.
Results of measurement of haemoglobin concentration in the pancreatic extract make the first possibility very unlikely and the second is purely hypothetical.

If certain pancreatic cells indeed have the capacity normally to synthesize S-type isoamylase, a major revision will be required in our present interpretation of isoamylase analysis. The rise in absolute values for S-type amylase that we have noted in some cases of acute pancreatitis (Fridhandler et al., 1972) would now have to be considered as possibly a reflection of the effect of the inflammatory process on those cells forming S-type isoamylase. The theoretical possibility would also have to be considered that the large concentrations of S-type isoamylase that have been noted in the serum and urine of two cases of pancreatic cancer (Ono et al., 1971; Ono and Eto, 1972; Shimamura et al., 1975), may be attributable to the dominant presence in these tumours of those pancreatic cells that synthesize S-type isoamylase.

Also relevant, and of great practical moment, is the question that these findings raise regarding the validity of interpretations given to clinical situations on the basis of isoamylase analysis (Berk and Fridhandler, 1975). Particularly at issue is whether pancreatic involvement can indeed be reliably detected or excluded on the basis of the isoamylase pattern if S-type isoamylase may also arise from the pancreas as well as the salivary glands, human milk (Fridhandler et al., 1974) lung cancer tissue (Ammann et al., 1973; Ueda et al., 1975) perhaps liver and Fallopian tube tissue (Fridhandler $e t$ al., 1972), and probably still other structures. Adding to this uncertainty is the hitherto unexplained finding of S-type isoamylase increase in acute pancreatitis and the preponderant S-type component found in certain cases of pancreatic cancer to which reference has already been made. The relative proportion of S-type isoamylase in pancreatic extract, however, is so small that any noxious stimulus or disease process affecting the pancreas would be expected to elicit a relatively overwhelming response of P-type isoamylase. It would seem reasonable to conclude for the present, therefore, 
that the danger of misinterpreting an isoamylase analysis in the vast majority of clinical instances in which P-type isoamylase is increased is very likely much more theoretical than real.

It is worthy of note that the manoeuvre used to demonstrate definitively the coexistence in the serum of an isoamylase component of low activity closely located in position to a major component of great activity were possible in this case because of the use of chromatographic techniques. The high capacity of the columns, the ability to identify special fractions and then to recover, isolate, concentrate, and subject them again to further chromatographic analysis constitute distinct advantages.

\section{References}

Ammann, R. W., Berk, J. E., Fridhandler, L., Ueda, M., and Wegmann, W. (1973). Hyperamylasemia with carci- noma of the lung. Annals of Internal Medicine, 78, 521-525.

Berk, J. E., and Fridhandler, L. (1975). Clinical application of amylase isoenzyme analysis. American Journal of Gastroenterology, 63, 457-463.

Fridhandler, L., Berk, J. E., Montgomery, K. A., and Wong, D. (1974). Column-chromatographic studies of isoamylases in human serum, urine and milk. Clinical Chemistry, 20, 547-552.

Fridhandler, L., Berk, J. E., and Ueda, M. (1972). Isolation and measurement of pancreatic amylase in human serum and urine. Clinical Chemistry, 18, 1493-1497.

Ono, T., and Eto, K. (1972). Practical application of amylase isozyme to disease diagnosis. Japanese Journal of Clinical Pathology, 20, 39-43.

Ono, T., Eto, K., Nakayama, J., and Yano, M. (1971). Abnormal amylase in a patient with malignant tumour. Medicine and Biology (Tokyo), 82, 53-56.

Shimamura, J., Fridhandler, L., and Berk, J. E. (1975). Non-pancreatic type hyperamylasemia associated with pancreatic cancer. American Journal of Digestive Diseases (in press).

Ueda, M., Fujii, M., Nakashima, Y., Hirata, H., and Ito, J. (1975). Hyperamylasemia of unknown origin. Japanese Journal of Gastroenterology, 72, 407-413. 